\title{
La digitalización de documentos en la Administración de Justicia
}

\author{
Digitization of records in the Administration of Justice
}

\author{
José Félix MUÑoz SORo (1), Javier NOGUERAS-Iso (2)
}

(1) Agencia Aragonesa para la Investigación y el Desarrollo (ARAID), Edificio I+D, Parque Tecnológico Walqa, 22197 Cuarte, España, jfm@unizar.es; (2) Depto. de Informática e Ingeniería de Sistemas, Universidad de Zaragoza, C/María de Luna 1, 50018 Zaragoza, España, jnog@unizar.es

\begin{abstract}
Resumen
El cambio a la utilización del expediente electrónico en la Administración de Justicia está suponiendo notables dificultades debido al enorme volumen de expedientes abiertos los cuales están exclusivamente en soporte papel o combinando elementos tanto en papel como electrónicos. Este artículo propone la adopción de una medida práctica para la sustitución progresiva del soporte papel: la digitalización, en el momento de su desglose, de los documentos aportados por las partes y su posterior conservación en formato electrónico en los archivos de la Administración.
\end{abstract}

Palabras clave: Documentos electrónicos. Digitalización. Administración de Justicia. Expedientes electrónicos. España.

\section{Introducción}

Los documentos son, desde hace 5000 años, el instrumento básico en el trabajo de las burocracias. En los últimos años, los sistemas informáticos han adquirido la capacidad de manejarlos; $y$, como consecuencia, una de las características más relevantes del momento actual en el desarrollo de la administración electrónica es la migración de los documentos en soporte papel a sus equivalentes en formato electrónico.

Esta migración se basa en un marco normativo que da soporte a la utilización de los documentos electrónicos, incluyendo su autenticación y su uso en la tramitación de los procedimientos. Pero la experiencia pone de manifiesto la notable dificultad que supone este cambio en las Administraciones y, especialmente, en el caso de la Administración de Justicia, en la que se centra este artículo. Las primeras dificultades aparecen en la recepción de la documentación en los registros, ya que estos deben convertirse en auténticos servicios de digitalización, capaces de trabajar en tiempo real, si se quiere que el interesado se lleve la documentación original. $\mathrm{Y}$, luego, una vez dentro de la organización, la tramitación de expedientes electrónicos precisa de un largo periodo de adaptación.

\begin{abstract}
The change in Administration of Justice towards the adoption of electronic files has experienced notable difficulties because of the huge volume of files that are currently open and only available in paper format, or combining elements both in paper and electronic. This article proposes a practical measure towards the progressive replacement of paper: the digitization, at the moment of the file breakdown, of the documents provided by the parts of a justice process, returning the originals to them, and their preservation in electronic format in the archives of the Administration.
\end{abstract}

Keywords: Electronic documents. Digitization. Administration of Justice. Electronic records. Spain.

Básicamente, hay dos estrategias posibles para esta migración: la introducción progresiva de los documentos electrónicos; y la consistente en el cambio, en un momento fijado, a una tramitación integralmente electrónica. La primera aparece como más viable desde un punto de vista económico y, de hecho, está ya produciéndose en las oficinas judiciales. En el artículo se expondrá como podría avanzarse en esta línea con medidas como la digitalización, en el momento de su desglose, de los documentos aportados por las partes y su conservación en formato electrónico. Esta medida se propone en Muñoz Soro (2013), un análisis para la mejora de la gestión de la documentación judicial, realizado por iniciativa de la Cátedra Logisman de la Universidad de Zaragoza para la Gestión Tecnológica Documental. En este artículo, después de describirla brevemente ( 2 ), se analizarán el marco legal $(\S 3)$ y los requerimientos técnicos $(\S 4)$ que deberán tenerse en cuenta a la hora de ponerla en marcha, para, finalmente, analizar su viabilidad y ventajas $(\S 5)$.

\section{Estrategias para la migración al expediente electrónico}

Una experiencia sobre la implementación del expediente electrónico en la Administración de 
Justicia española ha sido la realizada en las salas de lo contencioso de la Audiencia Nacional (Ramírez Sineiro 20, p. 151). En esta se creó un Servicio Común de Registro, Reparto, Digitalización y Archivo que recibe toda la documentación, la registra, la digitaliza y une a los expedientes electrónicos la copia electrónica auténtica de los documentos, que es la única que manejan los órganos judiciales. Esta estrategia podría denominarse de «día 0 », ya que en ella se establece un momento a partir del cual la totalidad de la tramitación ha de realizarse en formato electrónico. Previamente a este momento se realiza un proceso de digitalización masiva que permite que todos los documentos que los órganos judiciales estén manejando en el momento de la migración hayan sido convertidos a documentos electrónicos (Muñoz Soro 2013, p. 91).

Frente a esta iniciativa puntual, hay otras medidas, que se aplican a la totalidad de los órganos judiciales, y que conllevan la integración en el expediente de documentos electrónicos, aunque parece que ni el legislador ni muchos de los operadores jurídicos son aun conscientes de este hecho. Un ejemplo es la sustitución de las actas de las vistas judiciales en soporte papel por grabaciones de video y su conservación en sistemas específicos (como eFidelius). Previsiblemente, estos supuestos irán siendo cada vez más frecuentes; $y$, por ello, parece más realista pensar en una implantación progresiva del expediente electrónico y en un largo periodo de tiempo durante el cual convivirán los documentos en soporte papel y los electrónicos.

En esta línea, cabe plantearse medidas que promuevan una sustitución progresiva, como la ya mencionada digitalización y conservación en formato electrónico de los documentos aportados por las partes cuando son desglosados (separados del expediente). Esta operación se realiza normalmente antes del archivo del asunto. Actualmente, los documentos se fotocopian, el Secretario diligencia las fotocopias, y luego estas se unen al expediente. La aplicación de la medida consistiría en sustituir la realización de las fotocopias por la digitalización del documento, y la firma manual del Secretario por su firma electrónica, dando lugar a un testimonio en formato electrónico que es el que se conserva, asociado al expediente (Muñoz Soro 2013, p. 86). La medida presenta ventajas como que los documentos electrónicos generados son copias, dado que los originales se devuelven a las partes; no se da lugar a un coste operativo adicional, ya que actualmente se realizan fotocopias y el Secretario las firma manualmente; $y$, final- mente, que se consigue un efecto inmediato de reducción del volumen de papel archivado.

Para la aplicación de la medida, los documentos se escanearían, generando imágenes en formato PDF, tarea que es prácticamente igual a la actual de realización de las fotocopias. A continuación, se añadirían los metadatos y el Secretario firmaría los documentos con su firma electrónica avanzada. Para la conservación de los documentos una opción, a nuestro juicio poco adecuada, es asociarlos al expediente dentro de la aplicación de gestión. Otra sería disponer de un servicio accesible a través de Internet que permita enviar los documentos a un repositorio apropiado para su conservación. Este servicio devolvería la URI (dirección única) del documento, mediante la cual el órgano judicial podría recuperarlo en cualquier momento. Esta URI sí que podría conservarse en la aplicación de gestión, asociada al correspondiente expediente. De esta forma, en la base de datos de la aplicación de gestión únicamente se guardarían las URI, cuyo volumen es muy reducido, por lo que no se daría lugar a ninguna sobrecarga de la misma. Para recuperar el documento se utilizaría la URI guardada en el expediente. $Y$, como opción más segura, también sería posible utilizar de forma redundante ambos medios de conservación.

Para valorar la viabilidad de la medida propuesta y la forma en que debería desarrollarse, seguidamente se expone cuál es la normativa aplicable a la obtención y archivo de copias electrónicas auténticas de originales en papel.

\section{Normativa}

\subsection{Las copias electrónicas autenticas}

La obtención de copias mediante la digitalización de originales en papel se contempla en el artículo 28,3 de la Ley 18/2011, de 5 de julio, reguladora del uso de las tecnologías de la información y la comunicación en la Administración de Justicia (LUTICAJ). Esta dispone que se deberá garantizar la autenticidad, integridad y la conservación del documento imagen y que el proceso podrá hacerse de forma automatizada, utilizando un sello electrónico como medio para la autenticación. También podrán utilizarse otros medios previstos en el artículo 14,3 de la LUTICAJ, en particular, la firma electrónica del personal al servicio de la Administración de Justicia.

Por su parte, el artículo 29 contempla el archivo electrónico de documentos, disponiendo que

[...] los medios o soportes en que se almacenen documentos deberán contar con medidas de seguridad que garanticen la integridad, autenticidad, 
confidencialidad, calidad, protección y conservación de los documentos almacenados y ajustarse a los requerimientos que garanticen la compatibilidad e interoperabilidad de los sistemas informáticos.

Pero, para determinar los requerimientos que se deben cumplir en la aplicación de la medida que se propone, es preciso un grado de concreción muy superior. La base para ello deberían ser las normas de desarrollo de la LUTICAJ, en particular el Esquema judicial de interoperabilidad y seguridad, previsto en el artículo 47, el cual no ha sido aún publicado. Esta carencia puede ser subsanada en buena medida recurriendo al Real Decreto 4/2010, de 8 de enero, por el que se regula el Esquema nacional de interoperabilidad en el ámbito de la administración electrónica $(E N I)$. En primer lugar, porque hay un indudable paralelismo entre la regulación de la LUTICAJ y la de la Ley 11/2007, de 22 de junio, de acceso electrónico de los ciudadanos a los servicios públicos (LAE). En segundo lugar, porque el mencionado artículo 47 dispone que para la elaboración del Esquema judicial "se tendrá en cuenta lo establecido en los Esquemas nacionales de interoperabilidad y de seguridad".

Por ello, vamos a referirnos a las Resoluciones de desarrollo del ENI que tienen que ver de forma más directa con la digitalización de los documentos. Entre estas se encuentra en primer lugar la Norma Técnica de Interoperabilidad (NTI) de Documento electrónico, que define la estructura y otros aspectos básicos de los documentos electrónicos. Por su parte, la NTI de Procedimientos de copiado auténtico y conversión entre documentos electrónicos regula la obtención de copias electrónicas auténticas de originales en soporte papel. Estas copias se obtienen mediante la digitalización del documento a través de medios fotoeléctricos, la cual habrá de hacerse siguiendo lo establecido en la $\mathrm{NTI}$ de Digitalización de documentos. Las tres NTI mencionadas fueron publicadas en sendas Resoluciones de la Secretaría de Estado para la Función Pública, de 19 de julio de 2011.

Aunque las normas anteriores hacen referencia a los metadatos de los documentos, la más reciente NTI de Reutilización de recursos de información (Resolución de 19 de febrero de 2013) profundiza en esta cuestión, haciendo una propuesta de metadatos de catálogos de recursos basada en el vocabulario RDF DCAT (W3C 2013; European Commission 2013), incluyendo ejemplos de su serialización sobre RDF/XML y N3.

Finalmente, ha de mencionarse la NTI de Política de gestión de documentos electrónicos (Resolución de 28 de junio de 2012), en la que se establece la obligatoriedad de disponer de una política de gestión de documentos electrónicos; y se dan las directrices sobre su contenido y sobre los procedimientos para su elaboración y puesta en acción.

\subsection{Los expedientes electrónicos}

Para valorar la viabilidad de la medida propuesta también es preciso analizar, aunque sea muy brevemente, cuál sería su encaje en la regulación del expediente electrónico. Del tenor literal de la LUTICAJ se desprende que el expediente judicial electrónico deberá estar formado íntegramente por documentos electrónicos. Según Sanz y Salgado (2012, p. 574) este hecho «parece lógico y razonable» y, si se quieren incorporar documentos en soporte papel a un procedimiento cuyo expediente está en formato electrónico, la única opción posible es realizar copias electrónicas auténticas de los mismos. La consecuencia de esta posición es que la digitalización de los expedientes deberá hacerse siempre en su integridad y que, una vez trasladado un expediente al soporte electrónico, la oficina judicial deberá estar en disposición de convertir a este formato cualquier documento que se quiera incorporar al mismo. Además, sensu contrario cabe deducir que, a su vez, el expediente no electrónico deberá estar formado íntegramente por documentos en soporte papel.

Se trata, a nuestro juicio, de una óptica poco realista. Como ya se mencionó, la Ley $1 / 2000$, de 7 de enero, de Enjuiciamiento Civil (LEC) admite de facto la incorporación a los autos de documentos electrónicos, al regular en su artículo 147 la documentación de las actuaciones mediante sistemas de grabación y reproducción de la imagen y el sonido. Otra vía de introducción de los documentos electrónicos es la realización de los actos de comunicación a través del sistema LEXNET (Illán Fernandez, 2011, p. 106 y ss.). Por tanto, se utilizan documentos en soporte papel y electrónicos, al menos en la tramitación de los procedimientos civiles. Podría resolverse este problema teniendo en cuenta que ni la LEC ni la LUTICAJ exigen de forma expresa que a cada procedimiento corresponda un único expediente. En consecuencia, cabría plantearse la existencia de dos expedientes, uno en soporte papel y otro electrónico, asociados a un único procedimiento. En este caso, el único requisito que cabría exigir, según lo dispuesto en el artículo 26 de la LUTICAJ, sería que ambos expedientes compartieran un único identificador. 


\section{Requerimientos técnicos}

A continuación, veremos brevemente los requerimientos técnicos que se deberían cumplir en la aplicación de la medida que se propone, atendiendo a las tres fases en que se divide el proceso: digitalización, autenticación y archivo.

\subsection{Digitalización}

Una copia electrónica está compuesta, según la NTI de Documento electrónico, por la imagen electrónica y los metadatos. La imagen debe ser fiel al documento de origen, para lo que debe respetar la geometría del mismo en tamaños y proporciones y no podrá contener caracteres o gráficos que no figuren en este. El nivel de resolución mínimo para imágenes electrónicas será de 200 píxeles por pulgada. Cuando sea necesario, se realizará una "optimización automática de la imagen electrónica para garantizar su legibilidad, de modo que todo contenido del documento origen pueda apreciarse y sea válido para su gestión". También se contempla la necesidad de realizar las comprobaciones necesarias para garantizar que se producen imágenes fieles al documento original.

En cuanto a los metadatos, la mencionada NTI enumera un mínimo obligatorio, pero también permite asignar metadatos complementarios. Además de los correspondientes a los documentos, hay también un conjunto de metadatos que se asignan a los expedientes electrónicos. Respecto a estos últimos ha de tenerse en cuenta que existen notables diferencias entre la Administración de Justicia y las demás en la forma de referenciar los expedientes, por lo que probablemente este aspecto diferirá cuando se publiquen las normas de desarrollo de la LUTICAJ.

En cuanto al formato de la copia, según la misma NTI, se aceptarán los establecidos para ficheros de imagen en la NTI de Catálogo de estándares, entre los que se encuentran el PDF (ISO 32000-1:2008) y el PDF/A (ISO 19005$1: 2005$, ISO 19005-2:2011). Este último es el formato previsto para la conservación de los documentos a largo plazo (Electronic document file format for long-term preservation).

\subsection{Autenticación}

Si la copia es auténtica, deberá contener, además, la "firma de la imagen electrónica" y cumplir con lo establecido en la NTI de Procedimientos de copiado auténtico y conversión entre documentos electrónicos. Según esta, las copias electrónicas auténticas se firmarán mediante alguno de los sistemas de firma previstos en los artículos 18 ó 19 de la LAE, siendo el conte- nido de estos artículos equivalente al del 14,3 de la LUTICAJ. En consecuencia, la ley admite la firma electrónica avanzada como medio para la autenticación de las copias electrónicas y, dentro de esta, tanto los sellos electrónicos como los certificados de personal al servicio de la Administración de Justicia. En la medida propuesta la firma se realizaría de forma personal por parte de los Secretarios judiciales.

Las reglas a aplicar en la utilización de la firma electrónica vienen dadas en la NTI de Política de firma electrónica y de certificados de la Administración. Según esta la aplicación utilizada para la creación de la firma debe permitir que el usuario firmante seleccione el fichero que va a ser firmado. Antes de la generación de la firma deben realizarse varias verificaciones, interrumpiéndose el proceso si alguna no arroja un resultado positivo. Luego, en la firma se incluirán etiquetas con la siguiente información: 1) fecha y hora de firma, 2) certificado del firmante, 3) política de firma sobre la que se basa el proceso de generación de firma electrónica, y 4) formato del objeto original. También puede incluirse otra información adicional y sellos de tiempo sobre algunos o todos los objetos de la firma. Estos requisitos se cumplen por la aplicación ecoFirma, desarrollada por el Ministerio de Industria, Energía y Turismo, que podría utilizarse para la puesta en práctica de la medida.

En cuanto a los formatos para la firma electrónica de contenido, según la NTI de Catálogo de estándares, pueden ser los siguientes: XAdES, según la especificación ETSI TS 101 903; CAdES (ETSI TS 101 733) y PAdES (ETSI TS 102 778-3). El perfil mínimo de formato que se utilizará para la generación de firmas de contenido en el marco de una política será «-EPES», que es una extensión de la clase básica (BES), a la que añade información sobre la política de firma. El formato de la firma se reflejará en el metadato mínimo obligatorio "Tipo de firma", definido en la NTI de Documento electrónico.

\subsection{Archivo}

Una de las cuestiones más complejas para el archivo de copias electrónicas auténticas es garantizar la fiabilidad de las firmas electrónicas a lo largo del tiempo (Nualart Mercadé 2008, p. 195). Acertadamente, la NTI de política de firma electrónica y de certificados de la Administración establece un principio de proporcionalidad, afirmando que

la definición de medidas y procedimientos para archivado y custodia de firmas electrónicas se realizará atendiendo con proporcionalidad a los diferentes usos de la firma electrónica contemplados en el alcance y ámbito de aplicación de la política. 
Asimismo, dispone que, para garantizar la fiabilidad de una firma electrónica a lo largo del tiempo, se podrán utilizar dos mecanismos: a) "Firmas longevas mediante las que se añadirá información del estado del certificado asociado, incorporando un sello de tiempo, así como los certificados que conforman la cadena de confianza"; b) "Otros métodos técnicos que impedirán la modificación de la firma para la que se ha verificado su validez, de acuerdo a los requisitos establecidos en la política de firma correspondiente, y que habrá sido almacenada en un sistema en un momento del tiempo determinado".

Por tanto, las firmas longevas deben incluir un sello de tiempo que permita garantizar que el certificado era válido en el momento en que se realizó la firma. Para la conversión de una firma electrónica a firma longeva será necesario en primer lugar verificarla, validando la integridad de la firma, el cumplimiento de los estándares y que contiene las referencias obligatorias. A continuación se completará, obteniendo y anexándole las referencias a certificados (incluyendo los certificados del firmante y todos los que formen la cadena de certificación), así como la información referente al estado de los certificados, obtenida mediante la consulta a las listas de certificados revocados (CRL) o a directorios OCSP. Una vez generadas las firmas longevas, la política de firma definirá los procedimientos para mantener las evidencias y gestionar la actualización de las mismas.

También hay dos alternativas para la protección de la firma electrónica frente a la posible obsolescencia de los algoritmos. Una es la utilización de mecanismos de resellado, consistentes en añadir sucesivos sellos de tiempo utilizando los algoritmos que en cada momento tengan un nivel de seguridad adecuado. El otro es la conservación de la firma en un depósito seguro, garantizando la protección contra falsificaciones y asegurando la fecha exacta en que se guardó. En este caso no es preciso el sellado de tiempo.

\section{Conclusiones}

Cuando se compara la evolución del comercio y de la administración electrónica se observa que mientras que en el primero la necesidad de realizar operaciones comerciales de forma rápida y efectiva ha impulsado la toma de decisiones y acuerdos tanto a nivel tecnológico como organizativo, en el segundo se adoptaron con frecuencia requerimientos innecesariamente estrictos en cuestiones formales y de seguridad, lo que ha supuesto una barrera de tipo práctico muy importante. Este podría ser, de nuevo, el caso de la exigencia de un expediente integral- mente electrónico, la cual no existe en las entidades privadas que, sin embargo, avanzan cada vez más en la "oficina sin papeles".

En el artículo, se ha propuesto una medida para la progresiva adopción del expediente electrónico en la Administración de Justicia en base a la digitalización y conservación en formato electrónico de los documentos aportados por las partes. Desde el punto de vista práctico, tiene la ventaja de que los medios adicionales necesarios son los mínimos posibles. Pero, un punto clave es garantizar la seguridad en la conservación de los documentos electrónicos, y esta difícilmente puede obtenerse sin recurrir a repositorios especializados que sean accesibles a las oficinas judiciales de forma remota. Dado que su finalidad será únicamente el archivo y no la comunicación, deberían diseñarse de forma que solo el órgano judicial pudiera acceder a las copias. De esta forma, con pocos medios podría realizarse una experiencia piloto que permitiría avanzar en la modernización de la oficina judicial, familiarizando a sus miembros con el manejo de las copias electrónicas auténticas.

\section{Agradecimientos}

Este trabajo ha sido financiado por la Cátedra Logisman de la Universidad de Zaragoza para la Gestión Tecnológica Documental.

\section{Referencias}

European Commission (2013). DCAT Application Profile for data portals in Europe. https://joinup.ec.europa.eu/ system/files/project/DCAT-AP_Final_v1.00.pdf.

Illán Fernandez, José Maria (2009). La prueba electrónica, eficacia y valoración en el proceso civil. Cizur Menor: Aranzadi.

Muñoz Soro, José Félix (2013). Gestión y valoración de la documentación judicial en el nuevo contexto tecnológico. Zaragoza: Prensas Universitarias de Zaragoza.

Nualart Mercadé, Raimon (2008). iArxiu, un servicio de custodia y preservación a largo plazo de documentos electrónicos. // Blasco Díaz, J. L.; Fabra Valls M. J. (eds.). El documento electrónico: aspectos jurídicos, tecnológicos y archivísticos, Castellón de la Plana: Universitat Jaume I. 177-214.

Ramírez Sineiro, José Manuel (2011). La digitalización procedimental como imperativo hito tecnológico y normativo de la modernización de la justicia. // REGAP: Revista galega de administración pública. 42, 355-378.

Sanz Larruga, F. Javier; Salgado Seguin, Victor (2012). EI expediente judicial electrónico: documentos, copias y archivos. // Gamero Casado, Eduardo; Valero Torrijos, Julián (eds.). Las tecnologías de la información y la comunicación en la Administración de Justicia. Cizur Menor: Aranzadi. 563-606.

W3C (2013). Data Catalog Vocabulary (DCAT). W3C Working Draft, 12 March 2013. http://www.w3.org/TR/2013/ WD-vocab-dcat-20130312/.

Enviado: 2014-04-25. Segunda versión: 2014-06-27. Aceptado: 2014-06-27. 
